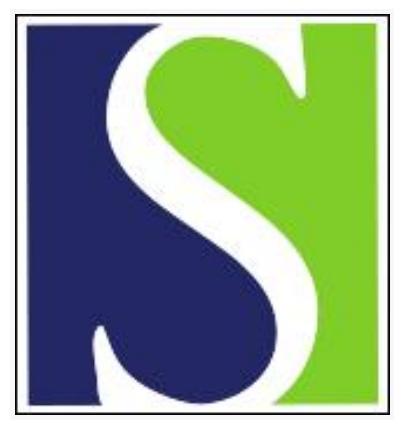

Scand J Work Environ Health 2011;37(4):276-287

https://doi.org/10.5271/sjweh.3156

Published online: 03 Mar 2011, Issue date: Jul 2011

Workplace bullying and mental distress - a prospective study of Norwegian employees

by Finne LB, Knardahl S, Lau B

Affiliation: National Institute of Occupational Health, NO-0033 Oslo, Norway. live.b.finne@stami.no

Refers to the following text of the Journal: 2001;27(1):63-69

The following articles refer to this text: 2011;37(4):259-261;

2012;38(1):38-46; 2012;38(3):218-227; 2012;38(3):187-192;

2012;38(4):291-297; 2013;39(5):468-476; 2016;42(5):359-370;

2018;44(3):283-290; 2020;46(4):339-349

Key terms: harassment; longitudinal; mental distress; Norway; Norwegian employee; occupational; prospective study; psychological health; workplace bullying

This article in PubMed: www.ncbi.nlm.nih.gov/pubmed/21373722 


\title{
Workplace bullying and mental distress - a prospective study of Norwegian employees
}

\author{
by Live Bakke Finne, MSc, ${ }^{1,2}$ Stein Knardahl, MD, PhD, ${ }^{1}$ Bjørn Lau, PhD ${ }^{1,2}$
}

Finne LB, Knardahl S, Lau B. Workplace bullying and mental distress - a prospective study of Norwegian employees. Scand J Work Environ Health 2011;37(4):276-287. doi:10.5271/sjweh.3156

Objectives Using a prospective design, the objective of this study was to determine the relationship between workplace bullying and mental distress.

Methods Altogether, 1971 Norwegian employees, recruited from 20 organizations, answered questions regarding workplace bullying and mental distress at both baseline and follow-up. Baseline data were gathered between 2004-2006, and follow-up data were gathered between 2006-2009. The time-lag between baseline and follow-up was approximately two years for all the respondents in all the organizations. The factors measured in the study were individual characteristics, mental distress measured with the Hopkins Symptom Checklist (HSCL-10), self-reported workplace bullying measured with a single item from the General Nordic Questionnaire for Psychological and Social Factors at Work (QPSNordic) and job demands and job control assessed by QPSNordic.

Results A hierarchical multiple linear regression analysis adjusted for mental distress, sex, age, job demands, and job control at baseline $[\beta=0.05,95 \%$ confidence interval $(95 \% \mathrm{CI}) 0.03-0.17]$ and a repeated measures ANOVA adjusted for sex and age $\left[\mathrm{F}(3,1965)=38.37\right.$; partial $\left.\eta^{2}=0.06\right]$ showed that workplace bullying predicted mental distress. Furthermore, a multiple binary logistic regression analysis adjusted for bullying, sex, age, job demands, and job control at baseline [odds ratio (OR) 2.30, 95\% CI 1.43-3.69] showed that mental distress was a predictor of bullying.

Conclusions We found support for the notion that self-reported workplace bullying is a predictor of mental distress two years later. Bullying had an independent effect on mental distress after adjusting for job demands and job control. Mental distress was also found to be a predictor of bullying, indicating that the reverse relationship is also important.

Key terms harassment; longitudinal; occupational; Norway; psychological health.

Workplace bullying and harassment is assumed to have a strong impact on the mental health of those affected (1). Using a prospective design, the objective of the present study was to determine the relationship between workplace bullying and mental distress.

Several cross-sectional studies have shown that being bullied in the workplace is associated with mental distress (2-6). Furthermore, victims of bullying as a group seemed to exhibit more symptoms of post-traumatic stress disorder (PTSD) than those who were not bullied (7-10).

Almost all studies of the relationship between workplace bullying and mental distress have had cross-sectional designs. To our knowledge, only three prospective studies have reported effects of workplace bullying on mental distress. Kivimäki and coworkers (11) found a strong association between workplace bullying and new reports of doctor-diagnosed depression. The risk of depression increased with prolonged bullying. However, depression at baseline predicted bullying at follow-up, indicating a reverse causality. Brousse and coworkers (12) reported serious psychiatric pathologies in a group of targets of workplace bullying who had previously presented no clinical history of psychiatric disorder. In contrast to these studies, a prospective study of work factors and psychological distress among nurses' aides (13) reported that bullying at work did not predict psychological distress.

In addition to the stressor-strain framework to explain effects of workplace bullying (eg, 4, 14-16), two other theoretical frameworks have been proposed.

1 National Institute of Occupational Health, Oslo, Norway.

2 Norwegian University of Science and Technology, Department of Psychology, Trondheim, Norway.

Correspondence to: Live Bakke Finne, National Institute of Occupational Health, Pb 8149 Dep, NO-0033 Oslo, Norway. [live.b.finne@ stami.no] 
Janoff-Bulman's $(17,18)$ cognitive theory of trauma (eg, 5, 7-10, 19) proposes that victims of systematic psychological harm develop PTSD (18) because their basic assumptions of the world as benevolent and meaningful and the self as worthy and capable of controlling external events are violated. Cross-sectional studies have given some evidence for different basic assumptions among victims of workplace bullying compared to others $(7,8,10,20)$. Social ostracism (eg, 19) means a systematic exclusion from a social group (21). Studies have reported that emotions like sorrow, hurt feelings, anxiety, depression, loneliness, jealousy, anger and shame are common responses to the experience of being rejected by other people (22-25).

Kivimäki and coworkers (11) found that depression at baseline predicted bullying at follow-up. This indicates that there may be individual characteristics that predispose an individual to being bullied. The perspective of individual antecedents to workplace bullying has been a controversial issue as "blaming the victim" may result (26). Cross-sectional studies have found that bullied individuals report lower levels of self-esteem (eg, 27, 28), higher levels of negative affect (eg, 29), and being more emotionally unstable (eg, 30, 31) than non-bullied individuals. However, the victim's attributions may affect the reporting of bullying (29). According to attribution theory, causal explanations will have consequences for how a person reacts to different events (32).

It seems that experiencing workplace bullying can contribute to mental distress, but individual characteristics may also contribute to the perception of bullying. The present study sought to answer the following questions: (i) Does workplace bullying predict mental distress? and (ii) Is there a reverse relationship between workplace bullying and mental distress? Two of the previous prospective studies $(11,13)$ investigated health-sector employees while the study by Brousse and coworkers (12) gave no information on the occupational status of the respondents. The present sample included 20 organizations from both public and private sector and represents a wide variety of job types. This strengthens the external validity of the present study compared to previous studies on workplace bullying and mental distress.

\section{Methods}

\section{Design}

The study was longitudinal and prospective. All variables were measured at baseline and follow-up two years later. In addition to the prospective design, the relationship between workplace bullying and mental distress was tested cross-sectionally at both survey points.

\section{Subjects}

The subjects were recruited from 20 Norwegian organizations, which were contacted and invited to participate. Baseline data were gathered from 2004-2006, and the follow-up data were gathered from 2006-2009. The time period between baseline and follow-up was approximately two years for all the respondents in all the organizations. The two-year follow-up period is a compromise. With limited knowledge of pathogenic mechanisms, it is not possible to know the optimal exposure-effect time. This study is part of a comprehensive project measuring a wide range of work factors and health outcomes and a two-year time-lag was considered the best compromise considering the various processes under study. Lastly, the two-year time-lag was what worked best for the companies that participated.

Of the 20 organizations involved, 10 were private and 10 were public, and they represented a wide variety of job types, with four municipalities, one insurance company, and two public organizations. The companies received written reports and oral presentations of the results.

When the employees and management of the companies had been informed at the organizational level, the companies supplied lists of names, addresses, sex, age, personal identification numbers, departments, and classification of the occupations of all their employees. Occupations were classified according to the standard classification of occupations (STYRK), developed by Statistics Norway (see http://www.ssb.no/) based on the International Standard Classification of Occupations (ISCO-88). After we received the lists, we mailed letters to all the employees. This letter contained general information regarding the purpose of the study and either a personal access code to the web-based questionnaire or a paper version of the questionnaire with a pre-stamped return envelope.

In the first survey (T1), 8928 employees were invited to participate and $3986(44.6 \%)$ answered both the question about bullying and the outcome measure HSCL-10. These respondents constituted the cross-sectional sample at T1. In the second survey (T2), 8836 employees were invited to participate and 3806 (43.1\%) responded. These constituted the cross-sectional sample at T2. Of the 8928 employees who were invited to participate in the first survey, 6361 were invited to participate in both the first and second surveys. Of these, 1971 (31\%) answered the question about bullying and the HSCL10 at both baseline and follow-up, and constituted the prospective sample.

The study was conducted in accordance with the World Medical Association Declaration of Helsinki and with the permission of the Data Inspectorate of Norway. 


\section{Measures of exposures, outcomes, and confounders}

Self-reported workplace bullying was measured by the "subjective" method (1) with a single item from the General Nordic Questionnaire for Psychological and Social Factors at Work (QPSNordic) (33): "Have you been subjected to bullying or harassment at the workplace during the last six months?" The response categories were "yes" and "no". The respondents were presented with a definition of bullying and harassment: "Bullying and harassment (badgering, niggling, offending somebody) is a problem at some workplaces and for some workers. To label something bullying or harassment, the offensive behavior has to occur repeatedly over a period of time, and the person confronted has to experience difficulties defending himself/herself. The behavior is not bullying or harassment if two parties of approximately equal "strength" are in conflict or the incident is an isolated event."

Mental distress during the last week was measured by 10 items from the Hopkins Symptom Checklist (HSCL-10). The HSCL is a valid, reliable (34), and widely used self-administered instrument designed to measure mental distress in population surveys (35) with 90-, 58-, 35-, 25-, 10-, or 5-item versions (36). Comparisons of HSCL-25, HSCL-10, and HSCL-5 have shown that the shorter versions perform almost as well as the full version (37). The HSCL-10 consists of 10 items on a four-point scale, ranging from " $1=$ not at all" to "4=extremely". Examples of items are "feeling tense or keyed up" and "feeling hopeless about the future". Responses with three or more missing items were excluded. Missing values were replaced with the individual mean. Cronbach's $\alpha$ for this scale was 0.86 at both $\mathrm{T} 1$ and $\mathrm{T} 2$.

Job demands (quantitative demands and decision demands) and job control (decision control and control over work intensity) were assessed by QPSNordic (33, 38,39 ). A mean score for job demands was computed by adding the dimensions quantitative demands (four items) and decision demands (three items), and for job control by adding the dimensions decision control (five items) and control over work intensity (four items). Responses are given along a five-point scale with a frequency scoring ranging from " $1=$ very seldom or never" to " $5=$ very often or always". Cronbach's $\alpha$ for job demands and job control at T1 was 0.76 and 0.81 , respectively.

The questionnaire also addressed background information, work organization, psychological and social factors at work (in addition to job demands and job control), organizational changes, attitudes towards work, personality, physical activity, smoking, alcohol use, mastery of work, work ability, and health complaints.

\section{Statistical analysis}

All statistical analyses were conducted with PASW Statistics (formerly SPSS), version 17.0 (IBM, Armonk, NY, USA).

Pearson's $\chi^{2}$ test was employed to execute nonresponse and attrition analyses. An independent-samples t-test was conducted to investigate attrition based on mental distress because HSCL-10 was used as a continuous variable.

Cross-sectional analyses. Univariate analyses of variance (ANOVA) were performed to test whether the group who experienced bullying had a different mean score on HSCL-10 from that of the group who did not experience bullying. The analyses were adjusted for sex and age.

Prospective analyses. Linear regression analyses were conducted to investigate whether bullying predicted mental distress. The unadjusted relationship between bullying at baseline and mental distress at follow-up was examined with a bivariate linear regression analysis. Next, a multiple hierarchical linear regression analysis was conducted, adjusted for mental distress at baseline, sex, age, job demands at baseline, and job control at baseline. The variables were entered in blocks with mental distress at $\mathrm{T} 1$ in block 1 , sex and age at $\mathrm{T} 1$ in block 2, bullying at $\mathrm{T} 1$ in block 3 , and job demands at $\mathrm{T} 1$ and job control at $\mathrm{T} 1$ in block 4.

Job demands and job control were entered in the same regression analysis whereas their correlation coefficient was low and not statistically significant ( $\mathrm{r}=0.01$, $\mathrm{P}>0.05$ ). Job demands and job control were also entered in separate regression analyses in block 4 , but this did not change the results.

To test whether prolonged exposure to bullying (ie, at both time points) constituted the greatest risk for mental distress, a repeated measures ANOVA was conducted. Four groups were created according to self-reported bullying: (i) group 1 was not bullied at either T1 or T2; (ii) group 2 was bullied at T1, but not at T2; (iii) group 3 was not bullied at T1, but was bullied at T2; and (iv) group 4 was bullied at both T1 and T2. The Games-Howell post hoc test was conducted to examine group differences in the mean scores on HSCL-10. This post hoc test should be used when the group sizes differ and when the variance is not equal (40). Paired samples t-tests were conducted within each of the groups to examine whether the result of the repeated measures ANOVA (that the score on HSCL10 was stable over the two measurement points) was replicated when each group was tested alone.

To investigate whether mental distress at baseline predicted bullying at follow-up, binary logistic regression analyses were conducted. First, the unadjusted 
relationship between mental distress at baseline and bullying at follow-up was examined. In the next step, a multiple binary logistic regression was conducted, adjusted for bullying at baseline, sex, age, job demands at baseline, and job control at baseline. All the variables were entered simultaneously.

\section{Results}

\section{Baseline characteristics and sample attrition}

The mean age of the respondents to the first survey was 43.97 years [standard deviation (SD) 10.26)], 65.2\% were women, $47.9 \%$ were married, $37.5 \%$ had children living at home, $28.2 \%$ had $13-16$ years of education, and $11.6 \%$ had management responsibilities. The corresponding figures for the respondents to both the first and second surveys were 44.84 years (SD 9.58), 63.7\%, $48.9 \%, 38.2 \%, 29.1 \%$, and $14.2 \%$, respectively (table 1 ).

Of the respondents to the first survey, $4.7 \%(\mathrm{~N}=188)$ reported that they had been subjected to bullying. The corresponding figure for the respondents to both the first and second surveys was $4.5 \%(\mathrm{~N}=88)$ at baseline (table 1). The mean HSCL-10 score for the respondents to the first survey was 1.37 (SD 0.40), and 1.36 (SD 0.40 ) for the respondents to both the first and second surveys (table 1).

The non-response analyses showed that those who were more likely not to respond, among the individuals who were invited to participate in the first survey, were aged $<30$ or $>59$ years old. The attrition analyses showed that the individuals who dropped out between the first and second surveys were more often: women, $<30$ or 50-59 years old, cohabiting or unmarried, and had no management responsibility.

Pearson's $\chi^{2}$ test showed that among the respondents to the first survey, there were no demographic differences (sex, age, marital status, number of children living at home, education, or supervisory position) between those who reported being bullied and those who reported that they had not been bullied. However, among the respondents to both the first and second surveys, we found more self-reported bullying among the unmarried and separated respondents $(\mathrm{P}<0.01)$.

\section{Cross-sectional relationship between bullying and mental distress}

The subjects who reported bullying had a higher mean score on HSCL-10 than those who did not report bullying at both $\mathrm{T} 1\left[\mathrm{~F}(1,3972)=119.02, \mathrm{P}<0.001\right.$; partial $\eta^{2}=$ $0.03]$ and at $\mathrm{T} 2[\mathrm{~F}(1,3800)=163.70, \mathrm{P}<0.001$; partial $\left.\eta^{2}=0.04\right]$ (table 2).

\section{Effect of bullying on subsequent mental distress}

Bullying at baseline significantly predicted mental distress at follow-up $[\beta=0.15,95 \%$ confidence interval (95\% CI) $0.22-0.38, \mathrm{P}<0.001$, bivariate linear regression analysis].

Bullying at baseline, adjusted for mental distress at baseline, sex, age, job demands at baseline and job control at baseline significantly predicted mental distress at follow-up ( $\beta=0.05,95 \%$ CI $0.03-0.17$; table 3 ). The $\beta$ value shows that less than $1 \%$ of the variance in mental distress at follow-up was explained by bullying at baseline.

The adjusted $\mathrm{R}^{2}$ for the regression model with only mental distress at baseline showed that this model explained $44.1 \%$ of the total variance in mental distress at follow-up. The model with mental distress at baseline, sex and age explained $44.2 \%$, but this change in the adjusted $\mathrm{R}^{2}$ was not statistically significant. The model with mental distress at baseline, sex, age, and bullying at baseline explained $44.4 \%$. This change was statistically significant $(\mathrm{P}<0.01)$. The full model with mental distress at baseline, sex, age, bullying at baseline, job demands at baseline and job control at baseline explained $44.5 \%$ of the variance in mental distress at follow-up, but this change in the adjusted $\mathrm{R}^{2}$ was not statistically significant.

Effect of prolonged bullying (at both time points) on mental distress

There was a main effect of bullying on mental distress, adjusted for sex and age $[\mathrm{F}(3,1965)=38.37, \mathrm{P}<0.001$; partial $\eta^{2}=0.06$; figure 1].

The Games-Howell post hoc test showed that employees who reported being bullied at both $\mathrm{T} 1$ and T2 had higher scores on HSCL-10 than non-victims $(\mathrm{P}<0.01)$. Employees who reported being bullied at either T1 or T2 also had a higher HSCL-10 score than employees who reported not being bullied $(\mathrm{P}<0.001)$. There was no statistically significant difference in the HSCL-10 scores of the employees who reported being bullied at both $\mathrm{T} 1$ and $\mathrm{T} 2$ and those who reported being bullied at either T1 or T2 $(\mathrm{P}>0.05)$.

The HSCL-10 score was stable over time for each of the four groups created according to self-reported bullying $\left[F(3,1965)=2.02, P>0.05\right.$; partial $\eta^{2}=0.00$; figure $1]$. This was confirmed with a paired-samples t-test for each of the groups $(\mathrm{P}>0.05)$.

There was a statistically significant relationship between sex and mental distress $[F(1,1965)=33.39$, $\mathrm{P}<0.001$; partial $\left.\eta^{2}=0.02\right]$. The relationship between age and mental distress was not statistically significant $\left[F(1,1965)=0.00, P>0.05\right.$; partial $\left.\eta^{2}=0.00\right]$. 
Table 1. Baseline characteristics of invited subjects, respondents a to the first survey, and respondents ${ }^{\mathrm{b}}$ to the $1^{\text {st }}$ and $2^{\text {nd }}$ surveys. [SD=standard deviation.]

\begin{tabular}{|c|c|c|c|c|c|c|c|c|c|c|c|c|}
\hline \multirow[t]{3}{*}{ Variable } & \multirow{2}{*}{\multicolumn{2}{|c|}{$\begin{array}{l}\text { Invited to } \\
\text { participate in } \\
\text { the } 1^{\text {st }} \text { survey } \\
(\mathrm{N}=8928)\end{array}$}} & \multirow{2}{*}{\multicolumn{4}{|c|}{$\begin{array}{l}\text { Respondents to the } 1^{\text {st }} \text { survey } \\
\qquad(\mathrm{N}=3986)\end{array}$}} & \multirow{2}{*}{\multicolumn{4}{|c|}{$\begin{array}{l}\text { Respondents to the } \\
1^{\text {st }} \text { and } 2^{\text {nd }} \text { surveys } \\
(N=1971)\end{array}$}} & \multicolumn{2}{|c|}{$P$ value ${ }^{c}$} \\
\hline & & & & & & & & & & & \multirow{2}{*}{$\begin{array}{l}\text { Invited } \\
\text { versus } \\
\text { respondents } \\
\text { to the } 1^{\text {st }} \\
\text { survey }\end{array}$} & \multirow{2}{*}{$\begin{array}{l}\text { Respondents } \\
\text { to the first } \\
\text { survey versus } \\
\text { respondents to } \\
\text { the } 1^{\text {st }} \text { and } 2^{\text {nd }} \\
\text { surveys }\end{array}$} \\
\hline & N & $\%$ & N & $\%$ & Mean & SD & N & $\%$ & Mean & SD & & \\
\hline Sex & & & & & & & & & & & 0.968 & 0.028 \\
\hline Male & 2853 & 32.0 & 1379 & 34.6 & & & 716 & 36.3 & & & . & . \\
\hline Female & 5374 & 60.2 & 2600 & 65.2 & & & 1255 & 63.7 & & & . & . \\
\hline Missing data & $701^{d}$ & 7.9 & $7^{d}$ & 0.2 & & & 0 & 0 & & & . & . \\
\hline Age & & & & & & & & & & & 0.000 & 0.000 \\
\hline$<30$ & 753 & 8.4 & 326 & 8.2 & & & 109 & 5.5 & & & . & . \\
\hline $30-39$ & 2147 & 24.0 & 1104 & 27.7 & & & 524 & 26.6 & & & . & . \\
\hline $40-49$ & 2509 & 28.1 & 1276 & 32.0 & & & 668 & 33.9 & & & . & . \\
\hline $50-59$ & 2137 & 23.9 & 1011 & 25.4 & & & 556 & 28.2 & & & . & . \\
\hline$>59$ & 684 & 7.7 & 265 & 6.6 & & & 114 & 5.8 & & & . & . \\
\hline Missing data & $698^{d}$ & 7.8 & $4^{d}$ & 0.1 & & & 0 & 0 & & & . & . \\
\hline Marital status & & & & & & & & & & & . & 0.013 \\
\hline Unmarried & . & & 329 & 8.3 & & & 144 & 7.3 & & & . & . \\
\hline Married & . & . & 1911 & 47.9 & & & 964 & 48.9 & & & . & . \\
\hline Cohabiting & . & . & 452 & 11.3 & & & 194 & 9.8 & & & . & . \\
\hline Widowed & . & . & 38 & 1.0 & & & 14 & 0.7 & & & . & . \\
\hline Divorced & . & . & 182 & 4.6 & & & 95 & 4.8 & & & . & . \\
\hline Separated & . & . & 52 & 1.3 & & & 25 & 1.3 & & & . & . \\
\hline Missing data & . & . & 1022 & 25.6 & & & 535 & 27.1 & & & . & . \\
\hline $\begin{array}{l}\text { Number of } \\
\text { children living at } \\
\text { home }\end{array}$ & & & & & & & & & & & . & 0.385 \\
\hline 0 & . & . & 1012 & 25.4 & & & 481 & 24.4 & & & . & . \\
\hline 1 & . & . & 526 & 13.2 & & & 256 & 13.0 & & & . & . \\
\hline 2 & . & 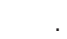 & 624 & 15.7 & & & 328 & 16.6 & & & . & . \\
\hline 3 & . & & 282 & 7.1 & & & 140 & 7.1 & & & . & . \\
\hline$>3$ & . & & 58 & 1.5 & & & 30 & 1.5 & & & . & . \\
\hline Missing data & . & . & 1484 & 37.2 & & & 736 & 37.3 & & & . & . \\
\hline Education & & & & & & & & & & & . & 0.143 \\
\hline 1-9 years & . & . & 216 & 5.4 & & & 96 & 4.9 & & & . & . \\
\hline $10-12$ years & . & & 901 & 22.6 & & & 445 & 22.6 & & & . & . \\
\hline $13-16$ years & . & . & 1123 & 28.2 & & & 573 & 29.1 & & & . & . \\
\hline$>16$ years & . & . & 316 & 7.9 & & & 143 & 7.3 & & & . & . \\
\hline Missing data & . & . & 1430 & 35.9 & & & 714 & 36.2 & & & . & . \\
\hline $\begin{array}{l}\text { Supervisory } \\
\text { position }\end{array}$ & & & & & & & & & & & . & 0.000 \\
\hline Top manager & . & & 41 & 1.0 & & & 26 & 1.3 & & & . & . \\
\hline $\begin{array}{l}\text { Middle } \\
\text { manager }\end{array}$ & . & & 421 & 10.6 & & & 255 & 12.9 & & & . & . \\
\hline $\begin{array}{l}\text { Do not have } \\
\text { management } \\
\text { responsibility }\end{array}$ & . & & 2225 & 55.8 & & & 1078 & 54.7 & & & . & . \\
\hline Missing data & . & & 1299 & 32.6 & & & 612 & 31.1 & & & . & . \\
\hline Bullying & & & & & & & & & & & . & 0.458 \\
\hline Bullied & . & & 188 & 4.7 & & & 88 & 4.5 & & & . & . \\
\hline Not bullied & . & & 3798 & 95.3 & & & 1883 & 95.5 & & & . & . \\
\hline Missing data & . & & 0 & 0 & & & 0 & 0 & & & . & . \\
\hline Mental distress & & & & & & & & & & & . & $0.066^{e}$ \\
\hline Mean score & & & & & 1.37 & 0.40 & & . & 1.36 & 0.40 & . & . \\
\hline Missing data & & & & & 0 & 0 & & . & 0 & 0 & . & . \\
\hline
\end{tabular}

a Respondents were defined as those who answered both the question about bullying and the HSCL-10 at the first survey.

${ }^{b}$ Respondents were defined as those who answered both the question about bullying and the HSCL-10 at both the first and second surveys.

c Pearson $\chi^{2}$ test.

${ }^{d}$ Sex and age were not identified for these individuals because their personal identification number could not be obtained.

e Independent-samples t-test. 
Table 2. Cross-sectional analyses: mean scores on HSCL-10 for bullied and not bullied subjects at $\mathrm{T} 1$ (N=3976) and at $\mathrm{T} 2$ ( $\mathrm{N}=3804)$. [SD=standard deviation.]

\begin{tabular}{|c|c|c|c|c|c|c|c|c|c|c|}
\hline \multirow[t]{2}{*}{ Group } & \multicolumn{5}{|c|}{$\mathrm{T} 1$} & \multicolumn{5}{|c|}{ T2 } \\
\hline & $\mathrm{N}$ & Mean & SD & $F(1,3972)$ & P-value & $\mathrm{N}$ & Mean & SD & $F(1,3800)$ & P-value \\
\hline Bullied & 186 & 1.67 & 0.56 & & & 184 & 1.71 & 0.59 & & \\
\hline Not bullied & 3790 & 1.36 & 0.38 & & & 3620 & 1.34 & 0.37 & & \\
\hline ANOVA ${ }^{a}$ & & & & 119.02 & 0.000 & & & & 163.70 & 0.000 \\
\hline
\end{tabular}

a Univariate analysis of variance adjusted for sex and age.

Table 3. Prospective analysis: bullying at baseline as predictor of mental distress at follow-up in a hierarchical multiple linear regression analysis ${ }^{a}(\mathrm{~N}=1839)$. [95\% $\mathrm{Cl}=95 \%$ confidence interval.]

\begin{tabular}{|c|c|c|c|c|}
\hline Independent variable & B & $\beta$ & $95 \% \mathrm{Cl}$ & P-value \\
\hline \multicolumn{5}{|l|}{ Block 1 b } \\
\hline Mental distress T1 & 0.68 & 0.66 & $0.65-0.72$ & 0.000 \\
\hline \multicolumn{5}{|l|}{ Block $2^{\text {b }}$} \\
\hline Mental distress T1 & 0.68 & 0.66 & $0.64-0.71$ & 0.000 \\
\hline Sex & 0.03 & 0.04 & $0.00-0.06$ & 0.036 \\
\hline Age & 0.00 & 0.00 & $-0.00-0.00$ & 0.954 \\
\hline \multicolumn{5}{|l|}{ Block $3^{\text {b }}$} \\
\hline Mental distress T1 & 0.67 & 0.65 & $0.63-0.71$ & 0.000 \\
\hline Sex & 0.03 & 0.04 & $0.00-0.06$ & 0.031 \\
\hline Age & 0.00 & -0.00 & $-0.00-0.00$ & 0.905 \\
\hline Bullying T1 & 0.10 & 0.05 & $0.03-0.17$ & 0.003 \\
\hline \multicolumn{5}{|l|}{ Block 4 b } \\
\hline Mental distress T1 & 0.66 & 0.65 & $0.63-0.71$ & 0.000 \\
\hline Sex & 0.03 & 0.03 & $-0.00-0.06$ & 0.098 \\
\hline Age & 0.00 & 0.00 & $-0.00-0.00$ & 0.897 \\
\hline Bullying T1 & 0.10 & 0.05 & $0.03-0.17$ & 0.006 \\
\hline Job demands T1 & 0.01 & 0.02 & $-0.01-0.03$ & 0.334 \\
\hline Job control T1 & -0.02 & -0.04 & $-0.04--0.00$ & 0.038 \\
\hline
\end{tabular}

${ }^{a}$ Adjusted for mental distress, sex, age, job demands and job control at baseline

${ }^{b}$ Adjusted $R^{2}=0.441$ for block 1 ; $D^{2}=0.001$ for block $2(P=0.109)$; $D R^{2}=0.003$ for block $3(P=0.003)$; $D^{2}=0.002$ for block $4(P=0.075)$.

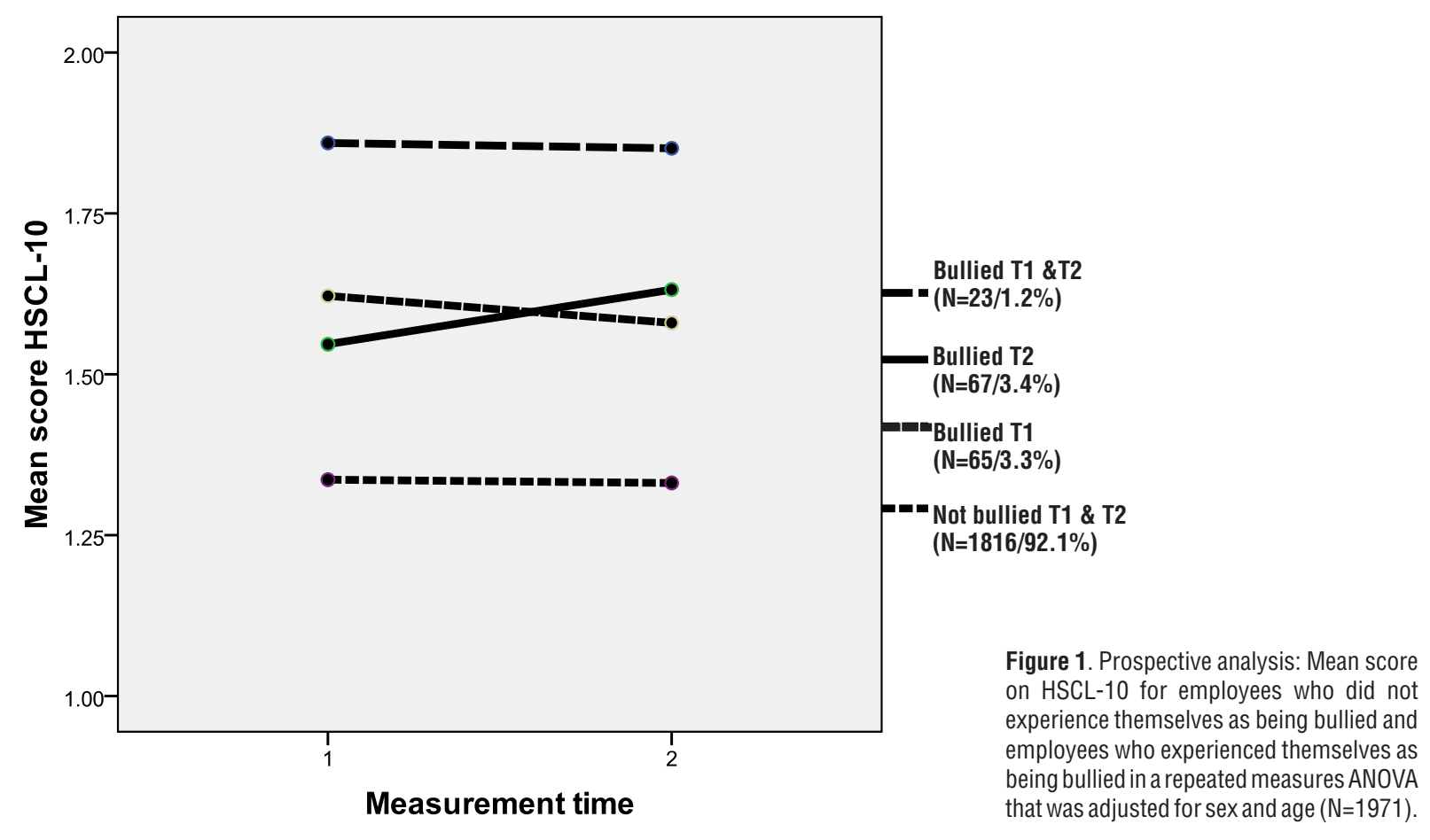




\section{Effect of mental distress on subsequent bullying}

Mental distress at baseline significantly predicted bullying at follow-up [odds ratio (OR) 3.18, 95\% CI 2.22-4.56, $\mathrm{P}<0.001$, bivariate binary logistic regression analysis].

Mental distress at baseline, adjusted for bullying at baseline, sex, age, job demands at baseline and job control at baseline significantly predicted bullying at follow-up (OR 2.30, 95\% CI 1.43-3.69; table 4).

\section{Discussion}

The present prospective study of Norwegian employees in many types of organizations and occupations showed that reporting being subjected to bullying at work predicted mental distress. Those who reported bullying at both baseline and follow-up or at either of the time points reported more mental distress than did employees who did not report bullying. Furthermore, mental distress was shown to be a predictor of bullying.

None of the four groups that were created based on their experience of bullying (figure 1) showed a significant change in the level of mental distress from baseline to follow-up. The strong regression coefficient between mental distress at baseline and mental distress at followup indicated that the level of mental distress was stable over time. Women reported more mental distress than men, consistent with other studies (see 37). Job control had an impact on mental distress at follow-up. In the analysis of the reverse relationship between bullying and mental distress, job control at baseline predicted workplace bullying.

Kivimäki and coworkers (11) found that workplace bullying predicts mental distress. However, contrary to the present study, Kivimäki and coworkers (11) found that there was a cumulative relationship between bullying and depression. In the study by Brousse and coworkers (12), $51 \%$ of the respondents reported that the bullying had lasted for $>2$ years. However, the impact of prolonged bullying was not analyzed. In the present study, we did not detect a statistically significant difference in the reported mental distress between the group that reported bullying at both baseline and follow-up and the groups that reported bullying at one of the time points. The lack of difference may be due to a low number of bullied subjects.

Our results indicate that employees who reported being bullied at both time points experienced quite severe symptoms of mental distress. The mean HSCL10 score for this group was 1.87 (SD 0.62) at baseline and 1.86 (SD 0.76) at follow-up. When HSCL-10 is applied as a population-based diagnostic measure, the
Table 4. Prospective analysis: mental distress at baseline as predictor of bullying at follow-up in a multiple binary logistic regression analysis ${ }^{a}(\mathrm{~N}=1812)$. [OR=odds ratio; $95 \% \mathrm{Cl}=95 \%$ confidence interval.]

\begin{tabular}{llrr}
\hline Independent variable & OR & \multicolumn{1}{c}{$95 \% \mathrm{Cl}$} & P-value \\
\hline Bullying T1 & 6.01 & $3.24-11.15$ & 0.000 \\
Sex & 0.95 & $0.56-1.59$ & 0.837 \\
Age & 0.99 & $0.97-1.02$ & 0.567 \\
Job demands T1 & 1.08 & $0.74-1.56$ & 0.703 \\
Job control T1 & 0.70 & $0.51-0.96$ & 0.026 \\
Mental distress T1 & 2.30 & $1.43-3.69$ & 0.001 \\
\hline
\end{tabular}

adjusted for bullying, sex, age, job demands and job control at baseline

conventional cut-off point of severe mental distress is 1.85 (36). The results of Brousse and coworkers (12) also indicated that targets of workplace bullying experience severe mental distress.

The finding from our study may be explained by Janoff-Bulman's cognitive theory of trauma $(17,18)$. A highly distressing or traumatic event presents information that is incompatible with an individual's existing cognitive schemas (41). Consequently, the individual is forced to realize that current basic assumptions may no longer be viable. Establishing new basic assumptions that includes the experience of being victimized is part of the coping process $(17,42)$, but for some victims this may be difficult. Hence, instead of resolving the cognitive-emotional crisis that may follow the traumatic event they continue to be in a chronic state of cognitive confusion and anxiety characterizing PTSD (see 7). To our knowledge, only three studies have investigated if those who report workplace bullying both show symptoms of PTSD and have shattered basic assumptions compared to non-bullied. These cross-sectional studies have shown that those who reported bullying showed symptoms of PTSD and considered themselves to be less worthy, less capable, unluckier, other people as less supportive and caring, the world as less controllable and just $(7,10)$ and the world as less benevolent $(8,7$, $10)$, than non-bullied control groups. However, none of these studies tested if the shattered basic assumptions mediated the relationship between workplace bullying and PTSD. Another cross-sectional study found that different justice beliefs did not mediate the relationship between self-reported bullying and adjustment dimensions (depression, pessimism and trust in the goodness of people) (20).

Another theoretical framework that has been proposed to explain the effect of bullying on mental distress is that of social ostracism (eg, 19). According to Williams (21) perceptions of being excluded or rejected (ie, social ostracism) from important social relationships threaten four basic social needs: a sense of belonging, self-esteem, control over the surroundings and the need 
for a meaningful existence. Einarsen \& Mikkelsen (19) argue that although the term bullying often refers to overt and direct aggressive behaviors, targets of bullying may also be subjected to covert behaviors, such as "being treated like air" or the "getting the silent treatment". Hence, social ostracism appears to be a common feature of bullying. However, to our knowledge, there are no studies investigating ostracism in relation to workplace bullying. Studies on other forms of ostracism have reported that exposure to social ostracism may lead to depression, anxiety, worry, pain, aggression, loneliness, jealousy, sorrow, and hurt feelings (22-25). Furthermore, studies have shown that a sense of belonging, control, and meaningful existence may diminish following ostracism (see 21). Einarsen \& Mikkelsen (19) have suggested that the cognitive theory of Janoff-Bulmann and the perspective of ostracism should be seen as parallel or even complementary in the understanding and explanation of the effects of workplace bullying.

According to this study and that of Kivimäki and coworkers (11), workplace bullying predicts mental distress. However, the present study showed that bullying explained only a small part of the variance in mental distress. The $\beta$ value of 0.05 (table 3 ) is low according to conventional standards. This implies that workplace bullying is not a substantial factor in the explanation of mental distress in a majority of employees. Consistent with this, a prospective study of work factors and psychological distress among nurses' aides (13) found that bullying at baseline did not predict mental distress at follow-up. One explanation for these diverse findings may be differences in the methods applied to assess mental distress and workplace bullying. Whereas Kivimäki and coworkers (11) measured bullying with no specific time frame and mental distress as doctordiagnosed depression, the present study and Eriksen and coworkers (13) applied a six-month time frame for bullying and measured mental distress (with the HSCL).

Both our study and that of Kivimäki and coworkers (11) demonstrated that mental distress predicts bullying. The OR of 2.30 (table 4) in the present study is in line with the OR of 2.46 from the study of Kivimäki and coworkers (11). There may be several explanations for this reverse relationship. Individual characteristics of those who report bullying (eg, 27-31) may make them targets. They may have had difficulties performing their jobs and therefore be perceived as "weak", or exhibit certain behavior that triggers bullying behavior from other people (eg, 31, 43). An anxious employee who struggles with social interaction may evoke aggressive behavior in others (44). Employees who have low self-esteem may trigger bullying because they may have more difficulties in defending themselves against aggressive behavior (45). Secondly, individuals with high levels of mental distress may have a tendency to interpret other people's statements and behavior as bullying. This may be seen in line with attribution theory (32). High levels of mental distress may induce hostile attributions for ambiguous behaviors. Consequently, this may lead to reporting of more bullying than those with low levels of mental distress (eg, 29, 43). As mentioned by Aquino \& Thau (43), it has been found that some victims of bullying presented an extremely suspicious view of the outside world (9).

Although the $\beta$ value in the present study of the prospective analysis of the relationship from workplace bullying to mental distress can be considered as weak, and the OR of the prospective analysis on the relationship from mental distress to bullying can be considered as strong, the strong OR of the reverse relationship does not exclude the effect of bullying on mental distress. The "small" effect size of the impact of bullying on mental distress may still be substantial (46). Workplace bullying is a phenomenon of low prevalence. Mental distress is a multifactorial phenomenon that has a wide range of explanatory variables. Hence, there will not be expected that one single factor (here workplace bullying) would explain a large part of the variation in mental distress. Furthermore, mental distress seems to be stable over time and a large part of mental distress at follow-up is explained by distress at baseline (table 3). Workplace bullying may still be severe for the individuals experiencing it and for the organizations where the bullying takes place. This may in particular be the case when it comes to prolonged bullying. This was shown by the mean value in HSCL-10 for the group reporting bullying at both $\mathrm{T} 1$ and $\mathrm{T} 2$ in the present study and by Kivimäki and coworkers (11).

The relationship between workplace bullying and mental distress may be influenced by other work factors. Both job demands (eg, 29, 47, 48) and job control (eg, 4, 28) have been shown to be related to workplace bullying in cross-sectional studies. Furthermore, high job demands and low job control have been reported to predict common mental disorders (49). Our results showed that only job control was significantly related to mental distress (table 3 ) and workplace bullying (table 4). The significant relationship between workplace bullying and mental distress was still present after adjusting for job demands and job control. Hence, the relationship between bullying and mental distress is unlikely to be attributable to these factors. Kivimäki and coworkers (50) found that high workload, low decision latitude, and self-reported workplace bullying were risk factors of new fibromyalgia, which seems related to depression (51). The strongest association was found between bullying and incidence of fibromyalgia, and this association was not affected by the adjustment for occupational group, workload, and decision latitude. We also tested the interactions between workplace bullying and job 
demands and between bullying and job control. Analyses are not shown. Neither of the interactions were statistically significant.

\section{Methodological considerations}

The strengths of this study include respondents from different organizations and job types, large sample size, adjusting for mental distress at baseline, and the use of validated instruments to measure workplace bullying and mental distress.

The response rate of only $31 \%$ for those in the prospective sample who answered both the question about bullying and the HSCL-10 at both T1 and T2 may have affected the external validity of the study. However, the generalization of the findings in this study is limited by the fact that it did not examine a random sample representative of the Norwegian or European working population. Hence, a low response rate has a limited impact on the external validity of the study. However, the low response rate may have affected the internal validity of the study if non-response was related to both bullying and mental distress (52).

There were differences between the population who was invited to participate in the first survey and the respondents. Those aged $<30$ years and $>59$ years were more likely not to respond. This selection bias constitutes a limitation in terms of the generalizability of the results. The dropouts between baseline and follow-up were more often women, aged $<30$ years or $50-59$ years, cohabiting or unmarried, and had no management responsibility. However, considering that there was no difference concerning mental distress or bullying between the dropouts and the responders and no demographic differences between the bullied and the non-bullied in the first survey, it is unlikely that this selection bias influenced the findings on the relationship between bullying and mental distress.

The use of self-report measures introduces reporting bias. Negative affectivity and social desirability may artificially inflate the reporting of both bullying and mental distress. However, the adjustment for mental distress at baseline should have minimized the bias related to negative affectivity.

Some factors may have led to an underestimation of the relationship between workplace bullying and mental distress. A "healthy worker effect" may have operated in different ways. The mean values for the HSCL-10 showed that most people in the sample did not experience symptoms of severe mental distress. Secondly, employees who reported bullying (and reported high levels of mental distress) may have changed jobs or left their jobs between baseline and follow-up. However, the attrition analyses showed that there were no systematic differences in bullying and mental distress between the respondents to the first survey and those who dropped out between the first and second surveys. Furthermore, the "healthy worker effect" will only lead to an underestimation of the relationship between bullying and mental distress if employees who were bullied and had high levels of mental distress did not answer the question about bullying and the HSCL- 10 .

In recent years, the different ways of measuring workplace bullying have been a debated topic in the field of workplace bullying research (eg, 53, 54). The method of measuring bullying used in this study could lead to an underestimation of the effect of bullying on mental distress. With the "subjective" method of measuring bullying, underreporting is likely because many victims may decline the victim role (1). The "operational" method, like the Negative Acts Questionnaire, which measures the frequency with which respondents have been subjected to various types of negative acts during the previous six months, has been claimed to yield more "objective" estimates of the prevalence of bullying. Studies have shown that applying the "operational" method yields higher prevalence rates than does the "subjective" method (eg, 7, 53, 55). Nielsen and coworkers (53) argue that these two methods for measuring bullying most likely provide valid, but supplementary, information on the phenomenon as they assess somewhat different aspects of workplace bullying. As in this study, Kivimäki and coworkers (11) measured bullying with a single item. The measure in our study has two advantages compared to that of Kivimäki and coworkers (11): (i) respondents report a time span of the last six months versus no specified timeframe (ie, their measure assessed bullying "currently" or "previously") and (ii) behavior as part of conflicts and isolated events were excluded.

Factors that have not been controlled for in the analyses could have also affected the results. The personality trait "neuroticism" may be a confounder in the relationship between workplace bullying and mental distress. Both a cross-sectional (5) and a prospective (12) study found that employees who reported bullying showed a higher degree of neuroticism than non-bullied subjects. However, the adjustment for mental distress at baseline in the present study probably attenuated the possible confounding effects of neuroticism (13).

It is possible that the time-lag of two years in this and the Kivimäki et al (11) study was not the most appropriate to detect the effects of workplace bullying on mental distress. There may have been short-term fluctuations in mental distress symptoms between baseline and follow-up that were not recorded with a time-lag of two years. According to De Lange and coworkers (56), there is limited knowledge of which time-lag should be applied when studying the health effects of different work factors. One study by Dormann \& Zapf (57) 
found that a time-lag of at least two years (compared with a four-year time-lag) was adequate to demonstrate a relationship between stressors at work, irritation, and depressive symptoms.

Our study showed that self-reported workplace bullying predicted mental distress in a diverse sample of both public and private organizations and a wide variety of job types, and not only in the health sector as found by Kivimäki and coworkers (11). That workplace bullying had an independent effect on mental distress after adjusting for job demands and job control emphasizes the significance of this phenomenon. Hence, early identification and routines for dealing with bullying in organizations are important. Furthermore, mental distress predicted self-reported bullying. Interventions aimed at reducing bullying in organizations should encompass this risk group. The findings that distress predicted reporting bullying and that mental distress is rather constant or stable over time may indicate that the distinct trauma and a PTSD framework $(17,18)$ does not adequately explain associations between bullying and mental distress.

One interpretation of the present results that is also mentioned by Kivimäki and coworkers (11) is that workplace bullying and mental distress interact in a vicious circle. However, it was not possible on the basis of either of these studies to determine how this circle begins. Consequently, to gain further insight into the relation between workplace bullying and mental distress, it will be necessary with prospective studies with large samples that collect data on more than two waves. Ideally, people should be followed from early in their working life.

\section{Acknowledgements}

This study was funded by the Norwegian Research Council. The authors would like to thank Anne Lene Andersen Watn, Jan Emberland, Jan Olav Christensen, Margrethe Schøning, and Shahrooz Elka for their participation in the administration of the survey. Jan Olav Christensen is thanked for his assistance in describing the subjects of the study. We would like to thank the participating companies for their involvement in this study. The authors declare that they have no conflicts of interest.

\section{References}

1. Einarsen S. Harassment and bullying at work: A review of the Scandinavian approach. Aggress Viol Behav. 2000;5(4):379401. doi:10.1016/S1359-1789(98)00043-3.
2. Niedhammer I, David S, Degioanni S. Association between workplace bullying and depressive symptoms in the French working population. J Psychosom Res. 2006;61(2):251-259. doi:10.1016/j.jpsychores.2006.03.051.

3. Rayner C, Hoel H, Cooper CL. Workplace Bullying. What We Know, Who is to Blame, and What We Can Do? London: Taylor \& Francis; 2002.

4. Zapf D, Knorz C, Kulla M. On the relationship between mobbing factors, and job content, the social work environment and health outcomes. Eur J Work Organ Psychol. 1996;5(2):215-237. doi:10.1080/13594329608414856.

5. Hansen ÅM, Hogh A, Persson R, Karlsson B, Garde AH, Ørbæk P. Bullying at work, health outcomes, and physiological stress response. J Psychosom Res. 2006;60(1):63-72. doi:10.1016/j.jpsychores.2005.06.078.

6. Vartia M. Consequences of workplace bullying with respect to the well-being of its targets and the observers of bullying. Scand J Work Environ Health. 2001;27(1):63-69.

7. Mikkelsen EG, Einarsen S. Basic assumptions of posttraumatic stress among victims of bullying at work. Eur J Work Organ Psychol. 2002;11(1):87-111. doi:10.1080/13594320143000861.

8. Glasø L, Nielsen MB, Einarsen S, Haugland K, Matthiesen SB Grunnleggende antagelser og symptomer på posttraumatisk stresslidelse blant mobbeofre [A study of basic life assumptions and post-traumatic stress disorder among victims of workplace bullying].Tids Nor Psykolfor. 2009;46(2):153-160.

9. Matthiesen SB, Einarsen S. Psychiatric distress and symptoms of PTSD among victims of bullying at work. Br J Guid Counsell. 2004;32(3):335-356. doi:10.1080/030698804100 01723558 .

10. Rodríguez-Munoz A, Moreno-Jiménez B, Vergel AIS, Hernández EG. Post-traumatic symptoms among victims of workplace bullying: Exploring gender differences and shattered assumptions. J Appl Soc Psychol. 2010;40(10):26162635. doi:10.1111/j.1559-1816.2010.00673.x.

11. Kivimäki M, Virtanen M, Vartia M, Elovainio M, Vahtera J, Keltikanagas-Järvinen L. Workplace bullying and the risk of cardiovascular disease and depression. Occup Environ Med. 2003;60(10):779-783. doi:10.1136/oem.60.10.779.

12. Brousse G, Fontana L, Ouchchane L, Boisson C, Gerbaud L, Bourguet D, et al. Psychopathological features of a patient population of targets of workplace bullying. Occup Med. 2008;58(2):122-128. doi:10.1093/occmed/kqm148.

13. Eriksen W, Tambs K, Knardahl S. Work factors and psychological distress in nurses' aides: a prospective cohort study. BMC Pub Health. 2006;6:290. doi:10.1186/1471-24586-290.

14. Hauge LJ, Skogstad A, Einarsen, S. The relative impact of workplace bullying as a social stressor at work. Scand J Psychol. 2010;51(5):426-433. doi:10.1111/j.14679450.2010.00813.x

15. Vie TL, Glasø L, Einarsen S. Health outcomes and selflabeling as a victim of workplace bullying. J Psychosom Res. 2011;70(1): 37-43. doi:10.1016/j.jpsychores.2010.06.007. 
16. Nielsen MB, Matthiesen SB, Einarsen S. Sense of Coherence as a Protective Mechanism Among Targets of Workplace Bullying. J Occup Health Psychol. 2008;13(2):128-136. doi:10.1037/1076-8998.13.2.128.

17. Janoff-Bulman R. Assumptive worlds and the stress of traumatic events: Applications of the schema construct. Soc Cognit. 1989;7(2):113-136. doi:10.1521/soco.1989.7.2.113.

18. Janoff-Bulman R. Shattered assumptions - towards a new psychology of trauma. New York: The Free Press; 1992.

19. Einarsen S, Mikkelsen EG. Individual effects of exposure to bullying at work. In: Einarsen S, Hoel H, Zapf D, Cooper $\mathrm{CL}$, editors. Bullying and emotional abuse in the workplace: International perspectives in research and practice . London: Taylor \& Francis; 2003. p127-144.

20. Adoric VC, Kvartuc T. Effects of mobbing on justice beliefs and adjustment. Eur Psychol. 2007;12(4):261-271. doi:10.1027/1016-9040.12.4.261.

21. Williams KD. Ostracism. Annu Rev Psychol. 2007;58:425452. doi:10.1146/annurev.psych.58.110405.085641.

22. Baumeister RF, Tice DM. Anxiety and social exclusion. J Soc Clin Psychol. 1990;9(2):165-195. doi:10.1521/ jscp.1990.9.2.165.

23. Leary MR. Responses to social exclusion: Social anxiety, jealousy, loneliness, depression, and low self-esteem. J Soc Clin Psychol. 1990;9(2):221-229. doi:10.1521/ jscp.1990.9.2.221.

24. Leary MR, Koch EJ, Hechenbleikner, NR. Emotional responses to interpersonal rejection. In: Leary MR, editor. Interpersonal rejection. New York: Oxford University Press; 2001. p145-166.

25. Chow RM, Tiedens LZ, Govan CL. Excluded emotions: The role of anger in antisocial responses to ostracism. J Exp Soc Psychol. 2008;44(3):896-903. doi:10.1016/j. jesp.2007.09.004.

26. Zapf D, Einarsen S. Individual antecedents of bullying: victims and perpetrators. In: Einarsen S, Hoel H, Zapf D, Cooper $\mathrm{CL}$, editors. Bullying and emotional abuse in the workplace: International perspectives in research and practice. London: Taylor \& Francis; 2003. p165-184.

27. Matthiesen SB, Einarsen S . Perpetrators and targets of bullying at work: Role stress and individual differences. Violence Vict. 2007;22(6):735-753. doi:10.1891/088667007782793174.

28. Vartia M. The sources of bullying - Psychological work environmentandorganizational climate. Eur JWorkOrganPsychol. 1996;5(2):203-214. doi:10.1080/13594329608414855.

29. Bowling NA, Beehr TA. Workplace harassment from the victim's perspective: A theoretical model and meta-analysis. J Appl Psychol. 2006;9(5):998-1012. doi:10.1037/00219010.91.5.998

30. Coyne I, Chong PSL, Seigne E, Randall P. Self and peer nominations of bullying: An analysis of incident rates, individual differences, and perceptions of the working environment. Eur J Work Organ Psychol. 2003;12(3):209-228. doi:10.1080/13594320344000101.

31. Glasø L, Matthiesen SB, Nielsen MB, Einarsen S. Do targets of workplace bullying portray a general victim personality profile? Scand J Psychol. 2007;48(4):313-319. doi:10.1111/ j.1467-9450.2007.00554.x.

32. Weiner B. "Spontaneous" causal thinking. Psychol Bull. 1985;97(1):74-84. doi:10.1037/0033-2909.97.1.74.

33. Dallner M, Elo A-L, Gamberale F, Hottinen V, Knardahl S, Lindstrøm K, et al. Validation of the General Nordic Questionnaire for Psychological and Social Factors at Work. Copenhagen: Nordic Council of Ministers, Nord; 2000:12.

34. Rickles K, Garcia CR, Lipman RS, Derogatis LR, Fischer EL. The Hopkins Symptom Checklist. Assessing emotional distress in obstetric-gynecological practice. Prim Care. 1976;3(4):751-764.

35. Derogatis LR, Lipman RS, Rickles K, Uhlenhut EH, Covi L. Hopkins Symptom Checklist (HSCL): A self-report symptom inventory. Behav Sci. 1974;19(1):1-15. doi:10.1002/ bs.3830190102.

36. Søgaard AJ, Bjelland I, Tell GS, Røysamb E. A comparison of the CONOR Mental Health Index to the HSCL-10 and HADS. Measuring mental health status in the Oslo Health Study and the Nord-Trøndelag Health Study. Norw J Epidemiol. 2003; 3(2):279-284.

37. Strand BH, Dalgard OS, Tambs K, Rognerud M. Measuring the mental health status of the Norwegian population: A comparison of the instruments SCL-25, SCL-10, SCL-5 and MHI-5 (SF-36). Nord J Psychiatry. 2003; 57(2): 113-118.

38. Christensen JO, Knardahl S. Work and neck pain: A prospective study of psychological, social, and mechanical risk factors. Pain. 2010;151(1):162-173. doi: 10.1016/jpain.2010.07.001.

39. Wännström I, Peterson U, Åsberg M, Nygren Å, Gustavsson P. Psychometric properties of scales in the General Nordic Questionnaire for Psychological and Social Factors at Work (QPSNordic): Confirmatory factor analysis and prediction of certified long-term sickness absence. Scan J Psychol. 2009;50(3):231-244. doi:10.1111/j.1467-9450.2008.00697.x.

40. Field A. Discovering Statistics Using SPSS. $2^{\text {nd }}$ Ed. London: Sage Publications Ltd; 2005.

41. Horowitz MJ. Intrusive and repetitive thoughts after stress. Arch Gen Psychiatry. 1975;32(11):1457-1463.

42. Janoff-Bulman R, Frieze IH. A theoretical perspective for understanding reactions to victimization. J Soc Issues. 1983;39(2):1-17. doi:10.1111/j.1540-4560.1983.tb00138.x.

43. Aquino K, Thau S. Workplace victimization: Aggression from the target's perspective. Annu Rev Psychol. 2009;60:717-741. doi:10.1146/annurev.psych.60.110707.163703.

44. Zapf D. Organisational, work group related and personal causes of mobbing/bullying at work. Int J Manpow. 1999;20(1):70-85. doi:10.1108/01437729910268669.

45. Matthiesen SB, Einarsen S.MMPI-2 configurations among victims of bullying at work. Eur J Work Org Psychol. 2001;10(4):467-484. doi:10.1080/13594320143000753.

46. Cortina JM, Landis RS. When small effect sizes tell a big story, and when large effect sizes don't. In: Lance CE, Robert $\mathrm{JV}$, editors. Statistical and methodological myths and urban legends. New York: Routledge; 2009. Routledge: New York. p287-308. 
47. Einarsen S, Raknes BI, Matthiesen SB. Bullying and harassment at work and their relationship to work environment quality: An exploratory study. Eur Work Organ Psychol. 1994;4(4):381-401. doi:10.1080/13594329408410497.

48. Agervold M. The significance of organizational factors for the incidence of bullying. Scand J Psychol. 2009;50(3):267-276. doi:10.1111/j.1467-9450.2009.00710.x.

49. Stansfeld S, Candy B. Psychosocial work environment and mental health - a meta-analytic review. Scand J Work Environ Health. 2006;32(6): 443-62.

50. Kivimäki M, Leino-Arjas $P$, Virtanen M, Elovainio M, Keltikanagas-Järvinen L, Puttonen S. Work stress and incidence of newly diagnosed fibromyalgia. Prospective cohort study. J Psychosom Res. 2004;57(5):417-422. doi:10.1016/S0022-3999(03)00620-2.

51. Suhr JA. Neuropsychological impairment in fibromyalgia. Relation to depression, fatigue, and pain. J Psychosom Res. 2003;55(4):321-329. doi:10.1016/S0022-3999(02)00628-1.

52. Hernán MA, Hernández-Díaz S, Robins, JM. A structural approach to selection bias. Epidemiology. 2004;15(5):615625. doi:10.1097/01.ede.0000135174.63482.43.

53. Nielsen MB, Skogstad A, Matthiesen SB, Glasø L, Aasland MS, Notelaers G, et al. Prevalence of workplace bullying in Norway: Comparisons across time and estimation methods. Eur J Work Org Psychol. 2009;18(1):81-101. doi:10.1080/13594320801969707.

54. Notelaers G, Einarsen S, De Witte H, Vermunt JK. Measuring exposure to bullying at work: The validity and advantages of the latent class cluster approach. Work Stress. 2006;20(4):288301. doi:10.1080/02678370601071594.

55. Agervold M. Bullying at work: A discussion of definitions and prevalence, based on an empirical study. Scand J Psychol. 2007;48(2):161-172. doi:10.1111/j.1467-9450.2007.00585.x

56. De Lange AH, Taris TW, Kompier MAJ, Houtman ILD, Bongers PM. The relationship between work characteristics and mental health: Examining normal, reversed and reciprocal relationship in a 4-wave study. Work Stress. 2004;18(2):149166. doi:10.1080/02678370412331270860.

57. Dormann C, Zapf D. Social support, social stressors at work, and depressive symptoms: Accounting for unmeasured third variables in a multi-wave study. J Occup Organ Psychol. 2002;75(1):33-58. doi:10.1348/096317902167630.

Received for publication: 16 August 2010 